\title{
Requirements for future control room and visualisation features in the Web-of-Cells framework defined in the ELECTRA project
}

Tornelli, Carlo; Zuelli, Roberto; Marinelli, Mattia; Morch, Andrei Z.; Cornez, Laurence

Published in:

Cired - Open Access Proceedings Journal

Link to article, DOI:

10.1049/oap-cired.2017.0772

Publication date:

2017

Document Version

Publisher's PDF, also known as Version of record

Link back to DTU Orbit

Citation (APA):

Tornelli, C., Zuelli, R., Marinelli, M., Morch, A. Z., \& Cornez, L. (2017). Requirements for future control room and visualisation features in the Web-of-Cells framework defined in the ELECTRA project. Cired - Open Access Proceedings Journal, 2017(1), 1425-8. https://doi.org/10.1049/oap-cired.2017.0772

\section{General rights}

Copyright and moral rights for the publications made accessible in the public portal are retained by the authors and/or other copyright owners and it is a condition of accessing publications that users recognise and abide by the legal requirements associated with these rights.

- Users may download and print one copy of any publication from the public portal for the purpose of private study or research.

- You may not further distribute the material or use it for any profit-making activity or commercial gain

- You may freely distribute the URL identifying the publication in the public portal 


\title{
Requirements for future control room and visualisation features in the Web-of-Cells framework defined in the ELECTRA project
}

\author{
Carlo Tornelli ${ }^{凶}$, Roberto Zuelli ${ }^{1}$, Mattia Marinelli ${ }^{2}$, Andrei Z. Morch ${ }^{3}$, \\ Laurence Cornez ${ }^{4}$ \\ ${ }^{1} R S E$, Milano, Italy \\ ${ }^{2}$ Department of Electrical Engineering, Technical University of Denmark, Lyngby, Denmark \\ ${ }^{3}$ SINTEF, Trondheim, Norway \\ ${ }^{4}$ CEA LIST, Gif sur Yvette, France \\ $凶$ E-mail: carlo.tornelli@rse-web.it
}

\begin{abstract}
This study outlines an overview of the general requirements for the control rooms of the future power systems $(2030+)$. The roles and activities in the future control centres will evolve with respect to the switching, dispatching and restoration functions currently active. The control centre operators will supervise on the power system and intervene when necessary - thanks to the maturation and wide scale deployment of flexible controls. For the identification of control room requirements, general trends in power system evolution are considered and mainly the outcomes of the ELECTRA IRP project, that proposes a new Web-of-Cell (WoC) power system control architecture. Dedicated visualisation features are proposed, aimed to support the control room operators activities in a WoC-oriented approach. Furthermore, the work takes into account the point of view of network operators about future control rooms and feedback about the proposed visualisation features, collected by means of interviews and questionnaires.
\end{abstract}

\section{Introduction}

The general trend towards a more flexible power system with high penetration of renewable energy sources, pervasive distributed control and automation, active participation of customers in power system management and increased influence of market mechanisms, impacts also on the role and activities of control room operators in charge of monitoring the power system state, prevent potential threats and resolve critical situations. As a consequence, future control rooms will be required to provide new functionalities and decision support mechanisms to the operators. In this frame, the ELECTRA IRP [1] has defined a set of general requirements for the future control centres. The requirements were identified considering both the global trends in power system operation and the impact on control room activities of the new Web-of-Cell (WoC) control architecture developed within the project $[2,3]$. Firstly, the methodology applied to identify future control room requirements is presented. Then, the main identified requirements are reported and discussed, including the opinion of network operator collected by means of a questionnaire and interviews.

Furthermore, control room visualisation features are suggested, enabling an easy assessment of the power system state and supporting the operators for taking decisions to mitigate critical situations. Feedback received from system operators about visualisation features is also reported.

\section{Methodology}

The methodology adopted to identify the requirements of the future control room centres was based on the analysis of trends in power system evolution from literature and interactions with power system operators $[4,5]$.

Specific public documents were selected and analysed, including results of EU projects (e.g. evolvDSO [6,7]), the documentation about relevant events occurred in power systems, such as blackouts, and the descriptions of existing software solutions for control rooms functions offered by relevant vendors.

The strategy adopted for organising the collected information is illustrated in Fig. 1: the functions and features required to future control rooms were identified both investigating the new roles and responsibilities of control room operators and the control technologies trends.

In this context the terms role, responsibility, service, function are intended as progressive details of duties in the system operators' organisations. A role is a high-level assignment that normally includes many responsibilities. The responsibility is a commitment to do something as answer to specific needs. For the actuation of his responsibilities, the operator addresses specific problems performing a series of services, which are made of elementary tasks called Functions. The collected information was organised according to the described methodology and summarised in tables as that shown in Table 1 .

As base for the interaction with power system operators, an online survey [8] was specifically developed for identifying the requirements of the future control rooms. The addressed topics were:

- the role of the human operator,

- the impact of smart grids applications,

- the density of control centres,

- the control centres external links,

- the demo projects experiences.

The answers received to the questionnaire - mainly from European DSOs - and the feedback collected during physical meetings with power system operators gave clear indications about general requirements for future control centres.

\section{Requirements for the future control centres}

In this section, the more important general requirements identified within the ELECTRA IRP are presented and discussed. 


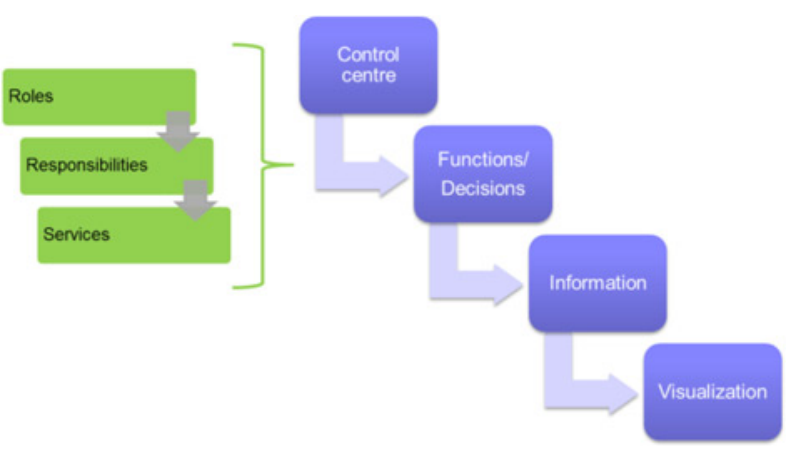

Fig. 1 Scheme adopted for the requirements extraction

Table 1 Example of summary table used to analyse roles, responsibility, service, and functions in future control rooms

\begin{tabular}{|c|c|c|c|}
\hline \multicolumn{4}{|c|}{$\begin{array}{l}\text { Control centre: DSO - regional } \\
\text { Role: contributor to system security (CSS) }\end{array}$} \\
\hline Responsibility & Service & Function & Information \\
\hline $\begin{array}{l}\text { TSO's requests } \\
\text { management }\end{array}$ & $\begin{array}{l}\text { response to } \\
\text { TSO's } \\
\text { short-term } \\
\text { requests }\end{array}$ & $\begin{array}{l}\text { perform load } \\
\text { transferring in } \\
\text { short term }\end{array}$ & $\begin{array}{c}\text { Load to be } \\
\text { transferred (e.g. } \\
\text { amount, location, } \\
\text { duration etc.). } \\
\text { Transferred load } \\
\text { (e.g. conditions, } \\
\text { how, what, where } \\
\text { etc.). } \\
\text { Network status. } \\
\text { Flexibility } \\
\text { information. }\end{array}$ \\
\hline- & - & - & - \\
\hline$R x$ & $S x$ & $F x$ & $I x$ \\
\hline
\end{tabular}

With respect to the current situation, the automation of the future power grids will be more extended and much more complex. It is foreseen a transition from nowadays operation, essentially based on knowledge and practical experience of the operator, to an extended use and interaction with automated systems. DSO control centres will manage a more automated and self-healing grid with monitoring and control extended to low-voltage networks and more focus on power quality and load flow management. This will require more extended information to take the correct decisions. Moreover, in a scenario of larger and more complex regulation of production and consumption than we know today, all these activities will fit with more distributed automated controls into the system and more accurate software tools to help decision making to be able to address the system complexity. New types of activities and decisions will be required to control room operators, needed to guarantee the quality of service in the presence of distributed production, leading to the introduction of more data and consequently new tools for their interpretation. The new tasks or old tasks in a new way, performed by DSO control centres will be network reconfigurations, troubleshooting team management, distributed resources monitoring and control, demand-response management of flexibility resources, information and communication technology (ICT) infrastructure management. Among the main activities that will be automated, or supported by new systems, the operators have indicated: automation for grid configuration, fault location and recovery.

Human supervision and the capacity to intervene in all situations are always required to satisfy customers' expectations on quality of the electric services. The automatic systems cannot manage all possible contingencies; however, they can help the operator to guarantee a quick human intervention and flexibility for a rapid recovery of the electricity distribution. The $24 / 7$ presence of a human operator is still recommended. Thanks to modern technologies, the operator will be able to operate several networks, also physically separated.

\subsection{Visualisation screens for distributed controls}

The distributed nature of the foreseen future power system control architecture defines the following control room requirements:

R1.1 The control room operator needs a topological view of the system with a clear indication of the network managed by each local controller.

R1.2 The status of local controllers has to be displayed to the operator together with indicators of normal/alert conditions and measures of achieved performance when the control is running.

\subsection{ICT infrastructure monitoring and management}

The ICT infrastructure, which includes both computing resources and communication equipment, is an integral part of the control system in smart grids. The involvement in grid operation of diffused resources and flexibilities and the extended use of communications set new challenges regarding the supervision and management of threats towards the new distributed control systems. The confidence on data shared has to be maximal and so cyber attacks should be counter measured by high IT security level. Feedback from operators suggests the organisation of information systems in two classes:

- technical systems for grid operation, necessary to guarantee the continuity and quality of service, with an 'extremely high' IT security level;

- systems for economical optimisation of the grid management, with 'high' security level.

Today, ICT independent department is the regular way for network operators to manage ICT infrastructure and counter measuring threats and it is foreseen to maintain this organisation. The needed future improvements focus on cyber attacks, also by adding knowledge, documentation and risk analysis. IT security should have dedicated 24/7 monitoring, automatic logging of malware and hacking managed by experts.

Network operators indicate the needs of close cooperation ad sharing of relevant information between ICT department and control centres to perform grid management. Grid operator has to be aware at any time of the state of ICT infrastructure and the following requirements for future control rooms can be identified:

R2.1 The status of each local controller displayed to the control room operator includes simple summary indicators related to the health status of the associated ICT infrastructure, including cyber security. The ICT status indicators will be based on real time data from the ICT monitoring system and should be simple and global; leaving detailed monitoring and troubleshooting to the ICT experts. R2.2 In case of alerts, errors or anomalous behaviours of a controller, the control room operator must be able to switch off the controller and to operate manually. Moreover, he can access to more detailed information (e.g. controller input/output data, detailed network status etc.) to identify the problem and to decide corrective actions.

Advanced control algorithms can implement adaptive behaviour that change control modes or controller parameters depending on the status, availability and performance of the ICT infrastructure.

R2.3 In case of controllers with different operational modes and automatic adaptive behaviour, the control centre operator has to be informed on the current active mode and to be alerted on changes of control mechanisms.

\subsection{Control centre architecture}

About the architecture of control centre applications, further requirements can be specified: 
R3.1 Modular and open architecture is preferred for future control centres.

R3.2 Software modules will use standardised interfaces, enabling easily integration of new applications or visualisation modules and facilitating maintenance/updating of control centre applications.

\subsection{Management of flexible resources}

The role of control room operator is to monitor the system in a defined area and its interconnections to maintain secure and stable operation, initiating control actions in response to critical events. The direct involvement of flexible resources in the network management will require the control systems to interact with them. Control centre operators have to be aware of actual use of the energy resources, the available flexibility and forecasts. The related requirements are:

R4.1 A set of observables for each controlled area/cell, including updated load and generation forecasts, are available to the operator to foresee possible occurring of critical situations.

R4.2 At any time, the control centre operator can access to the load and generation real time data and to the available flexibility, in terms of active power, reactive power and contribution to the inertia, in each portion of the network/cell.

\subsection{Requirements related to WoC}

Finally, the impact on control centres of the new proposed WoC control architecture was considered. In this perspective, the power system is organised in many interlinked control cells. Each cell contributes to frequency regulation by timely activating local reserves to maintain operating schedules; in addition, it keeps voltage within secure limits. The density of control rooms seems mainly related to organisational aspects than technical reasons and the current trend is to limit the number of control rooms and to concentrate in the same place also the supervision of several networks. Thus, in a WoC perspective, it can be assumed that the control room operator manages more than one cell with the following requirements:

R5.1 As a network operator may manage more cells, adjacent or not, a control centre has to provide to the operator all the necessary resources to monitor and control many cells.

R5.2 The boundary of each cell has to be shown on the grid topology representation for the control room operator.

R5.3 The state of each cell or sub-network can be displayed with different levels of detail.

R5.3.1 Synthetic indicators are used to inform the operator about normal conditions or constraints violation.

R5.3.2 The operator can access detailed measurements (voltages, currents etc.) by zooming in the cell.

R5.4 The operating state of each cell has to be monitored and displayed in real-time to ensure both continuous secure operation and appropriate response to disturbances. Whereas many systems are automatic, some responses may be manual.

\subsection{Controls coordination}

The control room operator supervises the mutual interaction among cells due to the actions of individual cell's controllers and can intervene to improve the global behaviour or the use of resources in the controlled area. Moreover, lessons learnt from the analysis of power system disturbances occurred in the past highlight system failures due to lack of observability outside the controlled area and poor coordination with other operators. This suggests additional requirements:

R5.5 Any additional information at the boundary of each cell in the controlled area will be accessible to the control room operator, in order to monitor and improve the coordination of control actions that affect neighbouring cells.

R5.6 In addition to the cells supervised by the control centre, it will be displayed also the summarised status of the neighbouring cells, under the responsibility of other network operators, in order to improve the communication and the coordination among operators of different areas.

\section{Control room visualisation features}

Based on the identified control room requirements, dedicated visualisation features are proposed, aimed to support the power system status awareness and to facilitate the operators decision process in a WoC context. The control of a power system starts with an effective visualisation strategy to manage the system complexity and the big amount of information required to properly operate it. It is necessary to keep the display and decision process as smooth and simple as possible to facilitate the control room operator's activities and keep high benefit in the human intervention.

The proposal is to adopt a high level visualisation of the controlled power system, as illustrated in Fig. 2, represented in the form of interconnected cells.

The state associated to each cell is displayed using a traffic light approach (i.e. green if there are no issues, yellow if there are critical conditions, red if there are issues), with possible extension of the colour coded conditions. In addition, synthetic data and cell information can be displayed in the same picture [9]. The operator can zoom and navigate in each cell to obtain further details so he can find out the origin of warnings or alarms (e.g. congestions, violation of voltage constraints etc.) and obtain the needed information to decide how to intervene. In case of contingencies, it is also possible to imagine an automatic presentation to the operator of a zoomed view of the affected area, driven by the local alerts activation.

The same visualisation approach may be applied not only to the present power system state but also to the forecasted ones. Making use of generation/consumption forecasting models and automatic analysis of trends of selected observables it is possible to anticipate risks and critical conditions approaching, enabling the operator to initiate preventive corrective actions.

Positive feedback on this proposal was collected interacting with stakeholders during a dedicated session at Congrés International des Réseaux Electriques de Distribution (CIRED) 2016 workshop and through an online survey [10]. Individual questions on what kind of information should be displayed to the operator, respectively, on a high-level view of the WoC and with a zoomed view of the cells. For the high-level view of the $\mathrm{WoC}$, the required mandatory information is:

- the geographical map of the controlled network,

- cells' current status (actual load and generation, frequency and its rate of change),

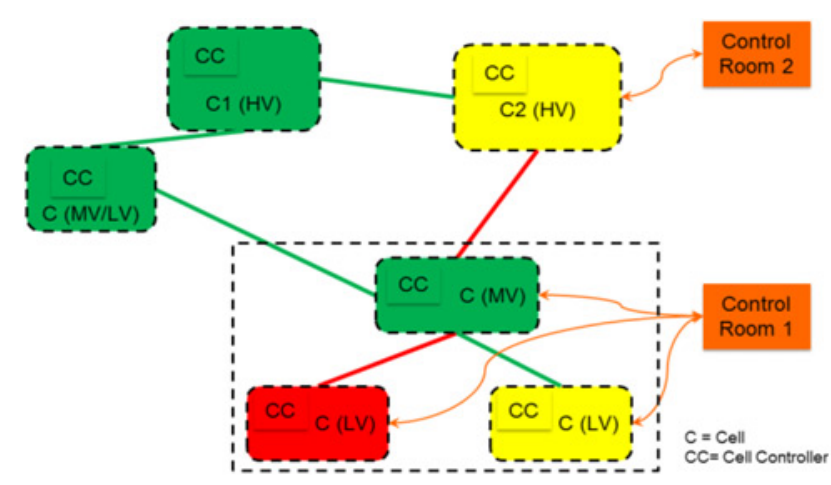

Fig. 2 Example of control room WoC visualisation with application of traffic light approach 
- status of cells' reserves (generation and storage),

- tie lines power exchange.

In a zoomed view of each cell, the following information is considered as mandatory:

- single line diagram of the network,

- line currents and power flows,

- bus voltages,

- tie lines currents and power exchange,

- current status and reserves of neighbouring cells,

- ICT network topology, status of ICT components and of communication services.

The general recommendation is to show to the operator only 'need to know' information during the different phases of activities, providing a straight guidance from signalled problem to the root cause.

Moreover, in a future scenario of highly distributed and automated controls, the preferable way of intervention in case of contingencies is to select among suggested corrective actions and decisions automatically proposed to the operator, depending on the cell and the power system status [11].

\section{Conclusion}

The main general requirements for future power system control rooms have been presented and discussed. Monitoring and management of the distributed control systems need to be available to the operators, as well as the status of ICT infrastructures. In order to address the complexity of the future power system and the increasing amount of data to be considered in day-by-day operation and to manage critical events, context aware visualisation features are recommended, focused only on information needed in each situation.

In the visualisation feature section, based on the discussions and interactions with different stakeholders, a dedicated visualistion strategy was presented. The recommendation was to have the possibility of representing the power system as interconnected cells and the states with a traffic light approach. Synthetic cell information is displayed on each cell and the operator can zoom in each cell for further details. Different layer of visualisations, depending on the level of interest (inter-cell, intra-cell and device) can be shown.

The identified control room requirements will be taken into account in the ELECTRA ongoing work about the tools to support the operating decisions of control room operators.

\section{Acknowledgment}

The research leading to these results has received funding from the European Union Seventh Framework Programme (FP7/20072013) under grant agreement no. 609687.

\section{References}

1 ELECTRA Integrated Research Programme. Available at http://www.electrairp.eu/, Accessed on 15 December 2016

2 Martini, L., Radaelli, L., Brunner, H., et al.: 'ELECTRA IRP approach to voltage and frequency control for future power systems with high DER penetrations'. CIRED 2015 Conf., AIM, 2015, vol. 1, pp. 210-220

3 Morch, A. Z., Jakobsen, S. H., Visscher, K., et al.: 'Future control architecture and emerging observability needs'. Proc. of IEEE Int. Conf. on Power Engineering, Energy and Electrical Drives (POWERENG), 2015, pp. 234-238

4 Sand, K.: 'Next generation control centres - state of art and future scenarios' Norwegian University of Science and Technology (NTNU), Trondheim, Technical Report 1/2012, 2012

5 Tornelli, C., Zuelli, R., Marinelli, M., et al.: 'Key requirements for the future control room functionality'. ELECTRA Internal Report R8.1, for public releasing at later stage, 2015

6 Schuster, H., Kellermann, J., Bongers, T., et al.: 'Definition of a limited but representative number of future scenarios'. evolvDSO Deliverable D1.1, 2012. Available at http://www.evolvdso.eu/Home/Results, Accessed on 10 June 2015

7 Bartolucci, G.: 'System use cases definition and functional and non-functional requirements for tools and methods, and definition of KPIs'. evolvDSO Deliverable D2.2, 2014. Available at http://www.evolvdso.eu/Home/Results, Accessed on 10 June 2015

8 Tornelli, C., Zuelli, R., Marinelli, M.: Future DSO control room requirements questionnaire. Available at https://goo.gl/forms/IJLcjt0x4gbbhiMn1, Accessed on 01 September 2015

9 Marinelli, M., Heussen, K., Strasser, T., et al.: 'Demonstration of visualization techniques for the control room engineer in 2030'. ELECTRA Deliverable D8.1, 2017

10 ELECTRA side event at CIRED 2016 workshop questionnaire. Available at http://www.electrairp.eu/index.php?option=com content\&view=article\&id=326 electra-engagement-and-consultation-following-cired-2016-workshop\&catid12\& Itemid $=1011$, Accessed on 06 September 2016

11 Rezkalla, M., Heussen, K., Marinelli, M., et al.: 'Identification of requirements for distribution management systems in the smart grid context'. Proc. of Universities Power Engineering Conf. (UPEC), 2015, pp. 1-6 